have to weigh this against its clinically important disadvantages of a measurable increase in the common side effects of nausea, vomiting, and hypertension. The improved efficacy of $10 \mathrm{IU}$ of oxytocin over $5 \mathrm{IU}$ in reducing the risk of postpartum haemorrhage implies a dose-response relation that warrants further investigation. Perhaps $15 \mathrm{IU}$ or $20 \mathrm{IU}$ would provide even greater protection against the risk of postpartum haemorrhage. This question deserves attention by way of an appropriately sized randomised controlled trial.

We especially thank the women who participated in the study and the midwives, without whose enthusiasm and support the trial would not have succeeded. Our thanks to the data monitoring committee (Mrs Vivien Gee, Dr Anne Jacquier, and Dr Vivienne Dawes); Alkie Sussa (computing services, King Edward Memorial Hospital); medical coding; obstetricians; the pharmacy and haematology departments at King Edward Memorial Hospital and Osborne Park Hospital; the National Perinatal Epidemiology Unit, Oxford; Dr Paul Burton and Ms Maxine Croft from the Western Australian research institute for child health, Perth, for encouragement and advice; and Sandoz, Basle and Australia, for their interest and financial help. We also thank Mrs Helen Howells, who helped with the typing. This study was made possible by grants received from the World Health Organisation (safe motherhood initiative), the National Health and Medical Research Council, and the King Edward Memorial Hospital Research Foundation. Our special thanks to Dr Diana Elbourne (perinatal trials service at the National Perinatal Epidemiology Unit, Oxford) for her expertise, encouragement, and guidance.

1 Royston E, Armstrong S. Preventing maternal deaths. Geneva: World Health Organisation, 1989:30-42.
2 Kwast B. Post partum haemorrhage: its contribution to maternal mortality. Midwifery 1991;7:64-7.

3 Report of Technical Working Group. The prevention and management of post partum haemorrhage. Geneva: World Health Organisation, 1990. (WHO/MCH/90.7)

4 Prendiville $W$, Elbourne D, Chalmers I. The effect of routine oxytocic administration in the third stage of labour: an overview of the evidence from controlled trials Brf Obstet Gymaecol 1988:95:3-16.

5 Garcia J, Garforth S, Ayers S. The policy and practice of midwifery study: introducion and meds.

6 Prendiville W, Harding JE, Elbourne DR, Stirrat GM. The Bristol third stage trial: "active" vs "physiological" management of the third stage of labour. BMF 1988;297:1295-300.

7 Begley CA. Comparison of "active" and "physiological" management of the third stage of labour. Midwifery 1990;6:3-17.

8 Prendiville W, Elbourne D. Care during the third stage of labour. In Chalmers I, Enkin M, Keirse M, eds. Effective care during pregnancy and childbirth. Oxford: Oxford University Press, 1988.

9 Elbourne D, Prendiville W, Chalmers I. Choice of oxytocic preparation for the routine use in the management of the third stage of labour: an overview of evidence from controlled trials. Br $\mathcal{F}$ Obstet Gynaecol 1988;295:17-30.

10 Baskett T. Management of the third stage of labour: a survey of practice among Canadian obstetricians. Fournal of Society of Obstetricians and Gynaecologists of Canada 1992 March/April:61-4.

11 Gilbert L, Porter W, Brown VA. Post partum haemorrhage-a continuing problem. Br f Obstet Gynaecol 1987;94:67-71.

12 Nieminen U, Jarvinen P. A comparative study of different medical treatments of the third stage of labour. Ann Chir Gynaecol 1963;53:424-9.

13 Vaughan-Williams C, Johnson A, Ledward R. Comparison of central venous pressure in the third stage of labour following oxytocic drugs and Diazepam. Fournal of Obstetrics and Gynaecology in the British Commonwealth 1974;81: 596-9.

14 Docherty P, Hooper $M$. Choice of an oxytocic agent for routine use at delivery. fournal of Obstetrics and Gynaecology 1981;2:60.

15 Dumoulin JG. A reappraisal of the use of ergometrine. Fournal of Obstetrics and Gynaecology 1981;1:178-81.

16 Symes JB. A study of the effect of erogmetrine on serum prolactin levels following delivery. Fournal of Obstetrics and Gynaecology 1984;5:36-8.

17 Elbourne DR. Prophylactic syntometrine vs oxytocin in third stage of labour. In: Enkin MW, Keirse MJNC, Renfrew MJ, Neilson JP, eds. Pregnancy and . Enkin MW, Keirse MJN, Renfrew MJ, Neilson JP, eds. Pregnancy and childbirth module. Oxford: Update Softwar

18 Mitchell G, Elbourne DE, Ashurst HA, Ibrahim G. The Salford third stage trial: oxytocin plus ergometrine versus oxytocin alone in the active management of the third stage of labour. Online fournal of Current Clinical Trials 1993 Aug 13:1993.

(Accepted 24 August 1993)
Academic Department of Public Health, St Mary's Hospital Medical School, University of London, London W2 1PG

David Miller, professor

Nicola Madge, senior research fellow

Judith Diamond, research statistician

Jane Wadsworth, senior

lecturer in medical statistics

Department of Community

Paediatrics, King's College

Hospital School of

Medicine and Dentistry,

University of London,

London

Euan Ross, professor

Correspondence to

Professor Miller.

$B M 71993 ; 307: 1171-6$

\title{
Pertussis immunisation and serious acute neurological illnesses in children
}

\author{
David Miller, Nicola Madge, Judith Diamond, Jane Wadsworth, Euan Ross
}

Abstract

Objective-To determine long term outcome in children who had a severe acute neurological illness in early childhood associated with pertussis immunisation.

Design-Follow up study of cases and matched controls.

Setting-Assessment of children at home and at school throughout Britain.

Subjects-Children recruited into the national childhood encephalopathy study in 1976-9 were followed up, with one of their two original matched controls, in 1986-9.

Main outcome measures-Performance in educational attainment tests; behaviour problems reported by teachers and parents; continuing convulsions; evidence of other neurological or physical dysfunction.

Results-Over $80 \%$ of cases and controls were traced. Case children were significantly more likely than controls to have died or to have some form of educational, behavioural, neurological, or physical dysfunction a decade after their illness. The prevalence of one or more of these adverse outcomes in case children who had been immunised with diphtheria, tetanus, and pertussis vaccine within seven days before onset of their original illness was similar to that in case children who had not been immunised recently. The relative risk for recent diphtheria, tetanus, and pertussis immunisation in children who had died or had any dysfunction in comparison with controls was 5.5 (95\% confidence interval 1.6 to 23.7). However, the number of cases associated with vaccine (12) was extremely small and statistically vulnerable, and other possible agents or predisposing factors could not be excluded.

Conclusions-Diphtheria, tetanus, and pertussis vaccine may on rare occasions be associated with the development of severe acute neurological illnesses that can have serious sequelae. Some cases may occur by chance or have other causes. The role of pertussis vaccine as a prime or concomitant factor in the aetiology of these illnesses cannot be determined in any individual case. The balance of possible risk against known benefits from pertussis immunisation supports continued use of the vaccine.

\section{Introduction}

The national childhood encephalopathy study was set up in Britain in 1976 after reports questioning the safety of pertussis vaccine ${ }^{12}$ had led to serious loss of confidence in the immunisation programme and a steep decrease in acceptance rates for this vaccine. ${ }^{34}$ The study aimed to examine the causes and outcome of severe acute neurological illnesses in young children with particular reference to the possible role of pertussis vaccine as an aetiological agent. ${ }^{5}$ The results showed a significant association between the onset of certain serious acute neurological illnesses and immunisation with diphtheria, tetanus, and pertussis vaccine in the previous seven days. ${ }^{5-7}$ Despite three years of active 
search, however, only a few cases associated with vaccine were detected, and the possibility of a causal relation was regarded as "suggestive" rather than proved. An even smaller number of children had evidence of persistent neurological deficits a year later, and it was therefore still less certain whether or not the vaccine could cause permanent brain damage, which at the time was the main focus of concern. It seemed safe, however, to conclude that if this occurred at all it was "a very rare event," and attribution of a cause in individual cases was regarded as "precarious."

The national childhood encephalopathy study has since been the subject of intense scrutiny both in the scientific literature and in the law courts. The validity of the methods used, the rigour of their application, and the significance of the results have been widely questioned. ${ }^{8-11}$ One criticism that was particularly relevant to the issue of possible brain damage was related to the assessment and interpretation of the outcome of the children's neurological illnesses carried out some $12-18$ months later. ${ }^{11}{ }^{11}$ This arose from three difficulties: firstly, that the children's developmental and neurological status was not assessed before their illness-deficits detected subsequently could thus have had other prior causes; secondly, that the neurological assessment of very young children is difficult-the validity of the methods used to determine their condition after the illness was questioned by some paediatricians; and, thirdly, that the outcome in control children, whose status would have provided a basis of comparison, was not medically assessed in the same way. The first of these difficulties is inescapable, although to limit its possible confounding effects, children reported to have shown prior deficits that were considered to be clinically important were excluded from the analyses of outcome in the national childhood encephalopathy study. With regard to the second and third difficulties, we now report the results of a 10 year follow up to determine the long term outcome, based on a set of standard tests in both case and control children at an age when their condition is likely to have stabilised and reliable assessment is easier.

\section{Methods}

The national childhood encephalopathy study was a case-control study based on the notification of cases of serious acute neurological illnesses in children aged 2-35 months (box 1) who were admitted to hospitals in Britain during a three year period in 1976-9. Details of the methods have been described previously. ${ }^{5}$ Two controls were selected by a random method for each case matched for age (within one month), sex, and area of residence. Immunisation histories were obtained independently for cases and for controls from health

TABLE I-Study population

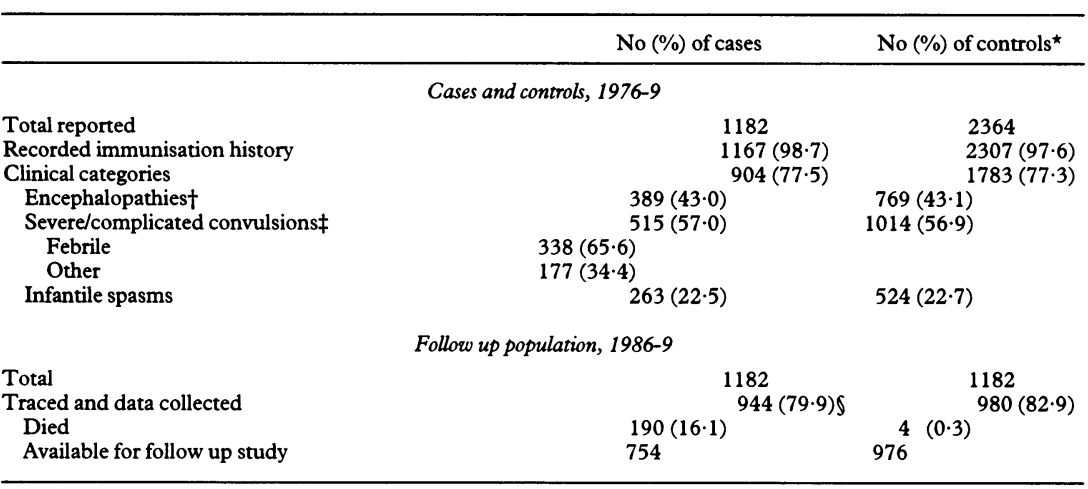

* Matched for age, sex, and area of residence.

tIncludes all children with a diagnosis in the first two and last categories in box 1.

fCases were categorised as "febrile" only if so described by the hospital clinician.

Includes 234 children with infantile spasms ( 28 of whom died) who are not included in the analyses of outcomes in this paper.
Box 1-Notification criteria in national childhood encephalopathy study

Children aged 2 to 35 months admitted to hospital with a possible diagnosis of:

- Acute or subacute encephalitis, encephalomyelitis, encephalopathy (including postinfectious encephalitis, but not pyogenic infections)

- Unexplained loss of consciousness

- Convulsions with a total duration of more than about half an hour, or followed by coma lasting two hours or more, or by paralysis or other neurological signs not previously present and lasting 24 hours or more

- Infantile spasms

- Reye's syndrome

authority and family doctor records. A total of 1182 cases that met notification criteria was reported: 1167 of the cases and 2307 matched controls had a recorded immunisation history. Table I shows the numbers of cases in each main clinical category. Children reported to have neurological symptoms or signs which persisted or recurred beyond 15 days after admission were examined by a study paediatrician using a standardised neurological and developmental assessment, ${ }^{12}$ which was repeated 12-18 months after admission. The outcome on the second occasion was used in previous reports on the national childhood encephalopathy study to estimate the prevalence of possible brain damage.

TABLE II-Response rates in children traced, excluding children who had died

\begin{tabular}{lcc}
\hline & $\begin{array}{c}\text { No (\%) of cases } \\
(\mathbf{n}=754)\end{array}$ & $\begin{array}{c}\text { Controls } \\
(\mathrm{n}=976)\end{array}$ \\
\hline Child ability tests & $691(91 \cdot 6)$ & $866(88 \cdot 7)$ \\
Teacher questionnaires & $678(89 \cdot 9)$ & $839(86 \cdot 0)$ \\
Medical examinations & $648(85 \cdot 9)$ & $792(81 \cdot 1)$ \\
Parent questionnaires & $584(77 \cdot 5)$ & $798(81 \cdot 8)$
\end{tabular}

A further follow up to identify any late deaths and to determine the late outcome in all surviving case children and one of the two original matched controls for each case was carried out in 1986-9 when most of the children were 10-12 years older (age range 7-15 years). The methods of follow up, including the selection of controls and methods of outcome assessment, have been described. ${ }^{13}$ In brief, children were traced by various methods including letters to patients, family doctors, or hospital doctors or through the NHS central register. Table I shows the numbers of cases and controls traced and available for follow up study. The children's educational abilities and social behaviour were assessed by widely used standard educational and behavioural assessment instruments, ${ }^{1420}$ and their current physical health was assessed by a specially devised standard clinical examination schedule (box 2). For children who were traced and still alive, questionnaires and assessment schedules were sent by post to their parents, class teachers, and school or family doctors with a request to complete them or to arrange for their completion. Response rates ranged from $77 \%$ to $92 \%$ (table II).

The results of the assessments were grouped into six areas of dysfunction: neurological, motor, sensory, educational, behavioural, and self care (box 3). Children whose degree of mental handicap prohibited the completion of educational tests were scored within the lowest ability grade for this function. Other functions that could not be tested by means of the standard schedules for any reason (for example, hearing, vision, or motor function in children unable to comprehend instructions) were categorised as not assessed. Where 


\begin{tabular}{|c|c|c|c|c|c|c|}
\hline & \multicolumn{3}{|c|}{ No (\%) of cases ${ }^{\star}$} & \multirow[b]{2}{*}{$\begin{array}{l}\text { No (\%) of } \\
\text { controls }\end{array}$} & \multirow[b]{2}{*}{$x^{2}$} & \multirow[b]{2}{*}{ p Value } \\
\hline & Encephalopathies & $\begin{array}{l}\text { Severe febrile } \\
\text { convulsions }\end{array}$ & $\begin{array}{l}\text { Other severe } \\
\text { convulsions }\end{array}$ & & & \\
\hline $\begin{array}{l}\text { Death } \\
\text { Dysfunction } \neq\end{array}$ & $116 / 330(35 \cdot 2)$ & $7 / 262(2 \cdot 7)$ & $39 / 118(33 \cdot 1)$ & $4 / 980(0.4)$ & $230.9 \dagger$ & $<0.001$ \\
\hline Neurological & $79 / 205(38.5)$ & $39 / 242(16 \cdot 1)$ & $46 / 74(62 \cdot 2)$ & $17 / 930(1 \cdot 8)$ & $266 \cdot 2 \dagger$ & $<0.001$ \\
\hline Motor & $82 / 178(46 \cdot 1)$ & $49 / 210(23 \cdot 3)$ & $42 / 65(64 \cdot 6)$ & $85 / 776(11 \cdot 0)$ & $126 \cdot 3 \dagger$ & $<0.001$ \\
\hline Sensory & $26 / 159(16 \cdot 4)$ & $21 / 213(9 \cdot 9)$ & $11 / 55(20.0)$ & $86 / 787(10.9)$ & $1.6 t$ & $<0.3$ \\
\hline Educational & $89 / 186(47 \cdot 8)$ & $48 / 227(21 \cdot 1)$ & $46 / 70(65 \cdot 7)$ & $40 / 836(4 \cdot 8)$ & $236.4 \dagger$ & $<0.001$ \\
\hline Behavioural & $31 / 183(16.9)$ & $22 / 219(10.0)$ & $14 / 60(23 \cdot 3)$ & $37 / 898(4 \cdot 1)$ & $45 \cdot 1 \dagger$ & $<0.001$ \\
\hline Self care & $32 / 170(18 \cdot 8)$ & $17 / 190(8.9)$ & $17 / 59(28 \cdot 8)$ & $18 / 796(2 \cdot 3)$ & $75 \cdot 5 t$ & $<0.001$ \\
\hline Any dysfunction or death & $254 / 330(77 \cdot 0)$ & $114 / 262(43 \cdot 5)$ & $100 / 118(84.8)$ & $237 / 980(24 \cdot 2)$ & $95 \cdot 1 \oint$ & $<0.001$ \\
\hline
\end{tabular}

$\star$ Excludes case children with infantile spasms.

+ With 1 degree of freedom for comparison of cases and controls.

With 1 degree of freed

SWith 2 degrees of freedom for comparison of encephalopathies, febrile convulsions, and other convulsions.

TABLE IV-Recent diphtheria, tetanus, and pertussis (DTP) vaccine by outcome at follow up in 1976-9 and in 1986-9 for cases and their matched controls

\begin{tabular}{|c|c|c|c|c|c|c|}
\hline & & & \multicolumn{4}{|c|}{ Children traced and assessed, 1986-9* } \\
\hline & \multicolumn{2}{|c|}{$\begin{array}{c}\text { All children, all } \\
\text { outcomes in 1976-9 }\end{array}$} & \multicolumn{2}{|c|}{$\begin{array}{c}\text { Dead or } \\
\text { dysfunction }\end{array}$} & \multicolumn{2}{|c|}{$\begin{array}{l}\text { Dead or educational, } \\
\text { behavioural, or } \\
\text { neurological } \\
\text { dysfunction }\end{array}$} \\
\hline & No & $\begin{array}{l}\text { No }(\%) \text { given } \\
\text { DTP vaccinet }\end{array}$ & No & $\begin{array}{l}\text { No (\%) given } \\
\text { DTP vaccinef }\end{array}$ & No & $\begin{array}{l}\text { No (\%) given } \\
\text { DTP vaccinet }\end{array}$ \\
\hline $\begin{array}{l}\text { Cases } \neq \\
\text { Matched controls } \\
\text { Relative risk ( } 95 \% \text { confidence interval) }\end{array}$ & $\begin{array}{r}904 \\
1783 \\
3 \cdot 3\end{array}$ & $\begin{array}{r}30(3.3) \\
23(1.3) \\
(1 \cdot 7 \text { to } 6 \cdot 5)\end{array}$ & $\begin{array}{r}367 \\
723 \\
5 \cdot 5\end{array}$ & $\begin{array}{r}12(3 \cdot 3) \\
6(0 \cdot 8) \\
1.6 \text { to } 23 \cdot 7)\end{array}$ & $\begin{array}{r}308 \\
606 \\
7 \cdot 3\end{array}$ & $\begin{array}{r}11(3.6) \\
3(0.5) \\
1.9 \text { to } 40.9)\end{array}$ \\
\hline
\end{tabular}

^Excludes case children with infantile spasms.

tWithin 7 days before "reference" date:

for cases: date of onset of acute neurological symptoms/signs;

for controls: date child reached same age as matched case at onset.

‡Excludes case children with recognised defects reported before initial illness.

possible, categorisation of the presence or absence of dysfunction was based on explicit clinical criteria for each variable or by reference to the distribution of the relevant variable in controls, as set out in box $3 .{ }^{13}$ To minimise possible bias, teachers and examining doctors were not told whether children were cases or controls or their immunisation status, and no reference was made to the results of any earlier assessment.

The analyses of results presented in this paper focus on the late outcomes of the severe acute neurological illnesses under study in relation to the history of diphtheria, tetanus, and pertussis immunisation in

\section{Box 2-Follow up assessments \\ School teachers}

Ability tests undertaken by children:

Raven's progressive matrices ${ }^{14}$

Mill Hill vocabulary scale ${ }^{15}$

Graded word spelling test ${ }^{16}$

Wide span reading test ${ }^{17}$

Graded arithmetic-mathematics test ${ }^{18}$

Questionnaires completed by teachers:

B(2) behaviour scale ${ }^{19}$

Standard schedule on pupil progress and background ${ }^{\star}$

School and family doctors

Standard neurological and general clinical examinations of children ${ }^{*}$

Past history from school health records ${ }^{\star}$

Parents

Questionnaires completed by parents:

A(2) behaviour scale ${ }^{20}$

Standard schedule on child's health and home background ${ }^{\star}$

*Schedules devised by study team for examination of children in the national childhood encephalopathy study
Box 3-Areas of dysfunction detected on examination or reported on questionnaires

Neurological dysfunction

Any of:

\section{Epilepsy}

Convulsions in past two years

Anticonvulsant drugs in past two years

Other neurological disorder reported by doctor

Motor dysfunction

Any of:

\section{Noticeable tremor}

Gross motor incoordination

Fine motor incoordination

Motor impersistence

Muscle weakness or spasticity in one or more limbs

Decreased or increased tendon reflexes in one or more limbs

Sensory dysfunction

Any of:

Hearing loss in both ears $(<25 \mathrm{~dB}$ at $250 \mathrm{~Hz}$ or

$<20 \mathrm{~dB}$ at other frequencies)

Visual impairment in best eye (near vision $<6$ or distant vision $<6 / 12$, or both)

\section{Educational dysfunction}

Global ability score lower than $95 \%$ of control children

Behavioural dysfunction

Any of:

Problem behaviour at home and at school

Hyperactive behaviour at home and at school

Unsociable behaviour at home and at school

Self care dysfunction

Poor bladder or bowel control, or both (wets or soils at least once a week), as reported by parent

both cases and controls, subject to certain exclusions. Previously reported analyses showed that cases of infantile spasms were not specifically associated with recent diphtheria, tetanus, and pertussis immunisation, ${ }^{21}$ and they are therefore excluded from all the analyses in this paper. Also, as in earlier reports, cases with recognised defects reported before their index illness (congenital defects involving the central nervous system, neurological problems persisting beyond the first month of life, retarded motor or intellectual development, or non-febrile convulsions) and their matched controls were excluded from the estimates of the risk of death or long term dysfunction after immunisation. Relative risks shown (see table IV) were estimated using the methods described by Miettenen, ${ }^{22}$ which allows inclusion of both matched controls in comparison with their respective cases. This method of analysis is identical with that used in previous reports on the national childhood encephalopathy study. ${ }^{57}$

\section{Results}

Children were categorised according to the clinical diagnosis made at the time of their entry to the national childhood encephalopathy study in 1976-9 and by the results of the outcome assessment at follow up in 1986-9. The numbers of cases in each of the original clinical categories that were followed up and assessed and the proportions with each type of dysfunction, with similar data for controls, are shown in table III. Cases in all clinical categories were more likely than controls to have died or to show some form of dysfunction. Those with prolonged or complicated febrile convulsions were less likely to have died or to show dysfunction in any area than those with 
encephalopathies or "other" severe convulsions. Overall seven $(3 \%)$ children with a diagnosis of severe febrile convulsions had died and another $107(41 \%)$ had some form of dysfunction; $116(35 \%)$ of those with encephalopathies had died and $138(42 \%)$ had dysfunction; $39(33 \%)$ of those with "other" severe convulsions had died and a further $61(52 \%)$ had dysfunction. By comparison, among the control children only $4(0.4 \%)$ had died and $233(24 \%)$ had any form of dysfunction This summary comparison, however, tends to understate the total burden of dysfunction among cases compared with controls. Among controls defects were mainly minor problems in hearing or vision $(86 ; 11 \%$ ) or in motor function $(85 \% ; 11 \%)$, which in most instances are unlikely to have a neurological basis, and multiple dysfunctions were unusual, whereas severe and multiple dysfunctions were relatively common among the case children. Moreover, for most controls a full assessment was possible and usually completed in all of the six areas of dysfunction so that any degree of impairment in any of the areas was likely to be detected and to place the child in the dysfunction category. By contrast, in many case children the severity of dysfunction in a key area-for example, intellect-was such that assessment in some other areas was impossible and had to be recorded as not tested.

A total of $30(3.3 \%)$ of the 904 case children in the original study whose immunisation history was known had received diphtheria, tetanus, and pertussis vaccine within seven days before onset of acute neurological symptoms or signs (table IV). This proportion was significantly greater than would have been expected by comparison with their matched controls (relative risk $3 \cdot 3 ; 95 \%$ confidence interval $1 \cdot 7$ to $6 \cdot 5)$.

Of the same 904 case children, 770 were reported to have had no apparent neurological abnormality before onset of their initial illness: $594(77 \%)$ of the 770 were traced and assessed at the latest follow up, and 367 $(62 \%)$ of the 594 had died (117 children) or showed evidence of dysfunction ( 250 children) as defined in box 3 . Of the 30 cases associated with vaccine in the original study, 26 had no apparent neurological abnormality before onset of their initial illness: 18 $(69 \%)$ of the 26 were traced and assessed and $12(67 \%)$ of the 18 had died (three children) or showed evidence of dysfunction (nine children). Thus of the 367 case children who were traced and who had died or had some dysfunction at follow up, $12(3.3 \%)$ had been immunised with diphtheria, pertussis, and tetanus vaccine within seven days before onset of their illness. This also was a significantly greater proportion than expected by comparison with their two matched controls (relative risk $5 \cdot 5 ; 1.6$ to $23 \cdot 7$ )

Some types of dysfunction included in this analysis were relatively minor or may not have had a neurological origin. The analysis was therefore repeated with more rigorous criteria for evidence of cerebral damage (death, educational or behavioural dysfunction, seizures, or other reported neurological disorders). This gave a slightly greater relative risk $(7.3 ; 1.9$ to

TABLE V-Dysfunction at follow up by vaccination status in previously normal children

\begin{tabular}{lcc}
\hline & $\begin{array}{c}\text { No (\%) given DTP } \\
\text { vaccine within 7 } \\
\text { days }\end{array}$ & $\begin{array}{c}\text { No (\%) not given } \\
\text { DTP vaccine } \\
\text { within 7 days }\end{array}$ \\
\hline Death & $3 / 18(16 \cdot 7)$ & $114 / 576(19 \cdot 8)$ \\
Dysfunction: & & \\
$\quad$ Neurological & $6 / 14(42 \cdot 9)$ & $114 / 440(25 \cdot 9)$ \\
Motor & $3 / 12(25 \cdot 0)$ & $128 / 381(33 \cdot 6)$ \\
Sensory & $0 / 11$ & $48 / 369(13 \cdot 0)$ \\
Educational & $5 / 14(35 \cdot 7)$ & $132 / 403(32 \cdot 8)$ \\
Behavioural & $4 / 15(26 \cdot 7)$ & $47 / 389(12 \cdot 1)$ \\
Self care & $1 / 13(7 \cdot 7)$ & $41 / 353(11 \cdot 6)$ \\
Any dysfunction or death & $12 / 18(66 \cdot 7)$ & $355 / 576(61 \cdot 6) \dagger$ \\
\hline
\end{tabular}

* As defined in box 3

$+x^{2}=0.035 ; p<0.9$
40.9). All three estimates of relative risk are significant, though they are not independent of each other.

Among the cases alone there was no significant difference between the proportions of recently vaccinated and of other children who later died or had any evidence of dysfunction (table $\mathrm{V}$ ). The number of recently vaccinated case children was too small for drawing conclusions about differences between clinical categories or between the various indices of dysfunction.

\section{Discussion}

This follow up of the children in the national childhood encephalopathy study provides more secure evidence of the long term consequences of severe acute neurological illnesses in early childhood than was hitherto available. It shows that all the types of illnesses studied may be associated with important permanent sequelae. Illnesses in children who had recently been immunised with diphtheria, tetanus, and pertussis vaccine do not seem to be different in this respect from similar illnesses in the remaining children. However, the number of affected children who had been immunised recently was extremely small; the relative risk estimates therefore have wide confidence intervals. The potential effects of other limitations of the study, including the possibility of errors or bias in the data collection and unknown confounding factors, remain uncertain and call for caution in the interpretation of the results.

The theoretical problems surrounding the methods of the national childhood encephalopathy study have been exposed to detailed examination and the raw data have been scrutinised extensively to try to determine the extent to which methodological flaws may have influenced the results. Some critics have suggested that error and bias in the conduct of the study led to an overestimate of the risks related to diphtheria, tetanus, and pertussis immunisation. ${ }^{89}$ These critics, however, have focused on the estimates of risk of events leading to permanent damage, for which the numbers of cases associated with vaccine are too small to reach any firm conclusions. Detailed exploration of the larger body of data on all acute neurological events, irrespective of outcome, has failed to find evidence of significant systematic error or bias in either direction. ${ }^{23-25}$ Exploration of the potential for confounding in the analysis found that no known factor was likely to account for the observed association. ${ }^{5}$ Fine and Chen have recently suggested that the national childhood encephalopathy study may have underestimated the risk of acute events by failing to control for confounding by factors predisposing to both avoidance of vaccination and the adverse reactions under study. ${ }^{26}$ This possibility was explored by a reanalysis excluding all cases and controls with any potential contraindications to immunisation; as Fine and Chen predicted, this produced a considerable increase in the relative risk for acute events. ${ }^{26} \mathrm{We}$ cannot be certain, however, how consistently such contraindications were applied in practice during the study period 1976-9 and how far such application may have influenced the findings. Although none of these problems can be fully resolved, examination of the evidence does not suggest that they operated to an extent that would require us to modify our general conclusions concerning the association between diphtheria, tetanus, and pertussis immunisation and acute neurological events.

Hitherto there has been no comparable study to support or to refute the findings of the national childhood encephalopathy study. Recently, however, the results of a study in the United States which used methods closely modelled on those of the national childhood encephalopathy study also showed a positive 
association between severe acute neurological illnesses (defined in the same way as in the national childhood encephalopathy study) and recent immunisation with diphtheria, tetanus, and pertussis vaccine. ${ }^{27}$ The numbers of cases and controls in this study were relatively small and the odds ratio did not reach statistical significance, though it was of similar magnitude to that found in the national childhood encephalopathy study.

Two independent scientific reviews of the national childhood encephalopathy study and other relevant studies have recently been published. Wentz and Marcuse reviewed critiques presented at a workshop organised in 1989 by the Institute of Medicine in the United States. ${ }^{1028}$ Both they and later a committee appointed by the Institute of Medicine at the instigation of the American Congress ${ }^{11}$ concluded that the evidence was consistent with a causal relation between diphtheria, tetanus, and pertussis vaccine and acute encephalopathy and that the range of excess risk was consistent with that estimated in the national childhood encephalopathy study. Both reviews also concluded that there was insufficient evidence to establish a causal relation between the vaccine and permanent neurological damage, which accords with the conclusions of the national childhood encepalopathy study. ${ }^{5}$

How often severe acute neurological illnesses in very young children, such as those reported in the national childhood encephalopathy study, cause permanent damage has hitherto been uncertain. No previous study has included sufficiently large numbers of children followed up for long enough to provide a satisfactory answer. The present study, moreover, offers a more robust assessment of the outcome of such illnesses than has hitherto been available, both because of the greater stability of children's conditions at older ages and because of the use of well tested standardised assessment instruments. In addition, identical information is available for both cases and controls. Our results, therefore, provide good evidence that illnesses such as those studied in the national childhood encephalopathy study, including a variety of encephalopathies and severe convulsions, both febrile and non-febrile, can have lasting sequelae as measured by various indices of brain function. This seems to be as true for cases associated in time with diphtheria, tetanus, and pertussis immunisation as for other cases. However, children with acute neurological illnesses, whether associated with vaccine or not, may have had a prior occult underlying condition that could have increased their susceptibility to external insults but that was not recognised at the time. A simple viral illness or immunisation with pertussis vaccine, for example, may cause fever and systemic upset, which in a susceptible child can provoke severe convulsions or encephalopathic symptoms. Furthermore, the ultimate outcome of what might have been a relatively innocent illness may be influenced by the presence of underlying pathology.

For these reasons, although children with severe acute neurological illnesses resulting in death or later dysfunction had a significant excess risk of recent diphtheria, tetanus, and pertussis immunisation when compared with controls, this does not prove that the vaccine was the sole or even the prime cause of either the illnesses or the adverse outcomes in these cases. It remains an open question as to whether or not such illnesses occur related to diphtheria, tetanus, and pertussis vaccine in children whose brains are structurally and functionally normal and in the absence of concomitant factors. Certainly, attribution of a cause in individual cases must be speculative.

What are the implications for immunisation policy? The national childhood encephalopathy study has

\section{Public health implications}

- Concern over the safety of pertussis vaccine in the 1970 s led to a serious decline in immunisation rates and large epidemics of whooping cough

- The national childhood encephalopathy study, conducted between 1976 and 1979, suggested there was a small excess risk of severe acute neurological events within seven days of pertussis immunisation, but the risk of permanent damage due to the vaccine, if any, was slight

- Follow up of cases and controls from this study for some 10 years has shown that significantly more children with such illnesses die or suffer subsequent educational, behavioural, or neurological deficits than expected by comparison with controls, but the number of cases associated with pertussis vaccine was small and statistically vulnerable

- The role of pertussis vaccine as a cause or concomitant factor in the aetiology of these illnesses remains unclear and cause cannot be attributed in individual cases

- The results confirm earlier conclusions that illnesses leading to death or brain damage after pertussis vaccine, if they occur at all, are extremely rare

- The balance of risk and benefit strongly favours continued use of pertussis vaccine

clearly shown that illnesses leading to death or brain damage after diphtheria, tetanus, and pertussis vaccine, if they occur at all, are extremely rare. In view of the relatively high mortality and morbidity that result from unmodified natural pertussis, ${ }^{4}$ there is good reason to continue to encourage the current use of diphtheria, tetanus, and pertussis vaccine, subject to the observance of appropriate contraindications. The recent change in the primary immunisation schedule in the United Kingdom from 4, 6, and 10 months for diphtheria, tetanus, and pertussis vaccine to 2,3 , and 4 months could have the benefit that, since infants are less susceptible to febrile convulsions in the first six months of life than later, such events are less likely to occur by chance in a time relation to immunisation and less likely to be provoked by fever induced by the vaccine.

We are grateful to all those children, parents, teachers, and doctors who assisted with this study and to the local and district health authorities and boards who kindly facilitated the work. We are especially indebted to Mrs Beryl Frost, project administrator, for her commitment and hard work, and to Professor C McManus, Professor W Yule, and Dr P Heaton for their advice. The study was supported by grants from the Medical Research Council, the Department of Health, and the Sir Samuel Scott of Yews Trust.

1 Kulenkampff M, Schwarztman JS, Wilson J. Neurological complications of pertussis inoculation. Arch Dis Child 1974;49:46-9.

2 Stewart GT. Vaccination against whooping cough: efficacy versus risks. Lancet 1977;i:234-7.

3 Joint Committee on Vaccination and Immunisation. The whooping cough epidemic 1977-79. In: Whooping cough. Reports from the Committee on Safety of Medicines and the foint Commitree on Vaccination and Immunisation. London: HMSO, 1981:170-84.

4 Miller DL, Alderslade R, Ross EM. Whooping cough and whooping cough vaccine: the risks and benefits debate. Epidemiol Rev 1982;4:1-24.

5 Alderslade R, Bellman MH, Rawson NSB, Ross EM, Miller DL. The national childhood encephalopathy study. In: Whooping cough. Reports from the Committee on Safety of Medicines and the foint Committee on Vaccination and Immunisation. London: HMSO, 1981:79-169.

6 Miller DL, Ross EM, Alderslade R, Bellman MH, Rawson NSB. Pertussis immunisation and serious acute neurological illness in children. $B M \mathcal{F}$ 1981;282:1595-9. 
7 Miller DL, Ross EM, Wadsworth J, Diamond J. Pertussis vaccine and whooping cough as risk factors for acute neurological illness in children. In: Proceedings of the fourth international symposium on pertussis, Geneva 1984, Develop Biol Stand. Vol 16, pp 389-94. S Karger, Basle, 1985.

8 Griffith AH. Permanent brain damage and pertussis vaccination: is the end of the saga in sight? Vaccine 1989;7:199-210.

9 Bowie JC. Lessons from the pertussis vaccine court trial. Lancet 1990;335: 397-9.

10 Wentz KR, Marcuse EK. DTP and serious neurologic illness: an updated review of the epidemiologic evidence. Pediatrics 1991;87:287-97.

11 Howson CP, Howe CJ, Fineberg HV, eds. Adverse effects of pertussis and rubella vaccines. A report of the Committee to Review the Adverse Consequences of Pertussis and Rubella Vaccines, Division of Health Promotion and Disease Prevention, Institute of Medicine. Washington, DC: National Academy Press, 1991:65-124.

12 Bellman MH, Rawson NSB, Wadsworth J, Ross EM, Cameron S, Miller DL. A developmental test based on the STYCAR sequences used in the nationa childhood encephalopathy study. Child Care Health Dev 1985;11:309-23.

13 Madge N, Diamond J, Miller D, Ross E, McManus C, Wadsworth J, et al

The national childhood encephalopathy study: a ten year follow-up. The national childhood encephalopathy
Dev Med Child Neurol 1993;suppl 68:1-118.

14 Raven JC, Court JH, Raven J. Manual for Raven's progressive matrices and vocabulary scales. Section 3: standard progressive matrices. London: H K Lewis, 1983

15 Raven JC, Court JH, Raven J. Manual for Raven's progressive matrices and vocabulary scales. Section $5 A$ : the Mill Hill vocabulary scale. London: $\mathrm{H} \mathrm{K}$ Lewis, 1982.

16 Vernon PE. Graded word spelling test. Sevenoaks: Hodder and Stoughton 1977.

17 Brimer A. Wide-span reading test manual. Windsor: NFER Nelson, 1984.
18 Vernon PE, Miller KM. Graded arithmetic-mathematics test: manual of instructions. Sevenoaks: Hodder and Stoughton, 1976.

19 Rutrer M. A children's behaviour questionnaire for completion by teachers: preliminary findings. F Child Psychol Psychiatry 1967;8:1-11.

20 Rutter M, Tizard J, Whitmore K. Education, health and behaviour. London: Longman, 1970.

21 Bellman MH, Ross EM, Miller DL. Infantile spasms and pertussis immunisation. Lancet 1983;i:1031-4.

22 Miettenen OS. Estimation of relative risk from individually matched series. Biometrics 1970;26:75-86.

23 Miller DL, Wadsworth J, Ross EM. Severe acute neurological illness: further analyses of the British national childhood encephalopathy study. Tokai Exp Clin Med 1988;13(suppl):145-55.

24 Miller DL, Wadsworth J, Ross EM. Pertussis vaccine and severe acute neurological illnesses: response to a recent review by members of the NCES team. Vaccine 1989;7:487-9.

25 Miller DL Wadsworth J, Ross EM. Safety of pertussis vaccine. Lancet 1990;335:655-6.

26 Fine PEM, Chen RT. Confounding in studies of adverse reactions to vaccine. Am f Epidemiol 1992;136:121-35.

27 Gale JL, Thapa PB, Bobo JR, Wassilak SGF, Mendelman PM, Foy HM. Acute neurological illness and DTP: report of a case-control study in Washington and Oregon. In: Manclark CR, ed. Sixth international symposium on pertussis, abstracts. Bethesda, Maryland: Department of Health and Human Services, 1990:228-9. (DHSS publication No (FDA) 90-1162.)

28 Marcuse EK, Wentz KR. The NCES reconsidered: summary of a 1989 workshop. Vaccine 1990;8:531-5.

(Accepted 24 August 1993)

\title{
Preregistration house officers in the Thames regions: changes in quality of training after four years
}

\author{
Jonathan H Gillard, Thomas H S Dent, Emma J Aarons, Helen L Crimlisk, Penelope J Smyth-Pigott, \\ Michael W N Nicholls
}

\section{Abstract}

Objective-To measure changes in the training and workload of preregistration house officers over four years.

Design-Postal questionnaire.

Setting-The Thames health regions.

Participants -1049 preregistration house officers.

Results-Response rate was $69 \%$ (725 replies). The proportion of house officers officially on duty $>83$ hours a week fell from at least $42 \%$ to $21 \%$, and the proportion officially on duty $\leqslant 72$ hours rose from no more than $9 \%$ to $40 \%$. Adequate guidance in breaking bad news increased from $25 \%$ to $46 \%$ ( $<<0.0001 ; 95 \%$ confidence interval for difference, $16.2 \%$ to $25 \cdot 8 \%$ ) and guidance in pain control increased from $36 \%$ to $46 \%(p<0.01 ; 5.0 \%$ to $15 \cdot 0 \%)$. The number of house officers attending an induction course increased from $61 \%$ to $94 \%(p<0.001 ; 28.9 \%$ to $37 \cdot 1 \%$ ). There was no change in the proportion unable to attend formal educational sessions because of clinical commitments or in levels of satisfaction with consultants' educational supervision. The median number of inpatients under house officers' care fell from 20 to 17 , but the numbers of patients clerked in an average week showed little change. House officers were less satisfied with the clinical experience their post provided (proportion dissatisfied rose from 30\% to $39 \%$; p $<0.01 ; 4.2 \%$ to $13.8 \%$ ) and less enthusiastic about recommending their post to a friend (proportion neutral or not recommending rose from $30 \%$ to $42 \%$, p $<0.0001 ; 7.9 \%$ to $16.9 \%$ ).

Conclusion-Despite progress in reducing hours of duty and providing induction courses, the training that hospitals and consultants provide for house officers is still unsatisfactory and inconsistent with the General Medical Council's recommendations.

\section{Introduction}

British medical graduates undergo a year's training in preregistration house officer posts approved for the purpose by their university before full registration with the General Medical Council allows them to take up posts providing more specialised training. In 1990 we published the results of a survey of the education and workload of preregistration house officers in the four Thames regions carried out by postal questionnaire in December 1988 and January 1989. ${ }^{1}$ Since then the GMC has published further recommendations on the training of house officers, ${ }^{2}$ the University of London has issued strict stipulations to hospitals on which tasks are inappropriate for house officers, ${ }^{3}$ and the Department of Health has set out a programme to reduce the hours of work of doctors in training. ${ }^{4}$ In this paper we report the changes in the quality of training of house officers in the Thames regions since our first survey.

\section{Method}

The survey was conducted by postal questionnaire. To ensure comparability of the results the second survey followed closely the method of the first. After a pilot study we wrote to all 1049 house officers in the Thames regions telling them about the survey and asking for their participation. The first questionnaires were addressed to individual house officers and distributed through clinical tutors in late November 1992. Non-responders were followed up through the tutors in early January 1993, but the response rate was less than $50 \%$. A third questionnaire was sent to nonrespondents at the address they had used when registering with the GMC. This last step had not been necessary in 1988-9.

The questionnaire requested information on the respondents' undergraduate medical education, induction courses, formal educational meetings, educational supervision, hours of duty, workload, attitude to their posts, and whether they would recommend the post to a friend. These questions were identical to those asked in the first survey, except for those about out of hours duties. Space was provided in each section for comments. Copies of the questionnaire are available from the authors. Data analysis was by 